\title{
A Linguistic Perspective of EU’s Migrant Education Policy
}

\author{
LIU Xu-liang \\ University of Chinese Academy of Social Sciences, Beijing, China
}

\begin{abstract}
Language education, especially the host country language, plays a key role in helping the migrants to be further adapted and integrated to the local society, culture, education, and employment. Sufficient language skill of the host community is prerequisite for the migrants to enjoy the equal rights with the locals in political, social, and professional life. Governments at different levels and in different countries should make incessant efforts to help them get linguistically equipped for a better life and work.
\end{abstract}

Keywords: migrant population, linguistic policy and pursuit, linguistic support, challenges and improvements

\section{Background}

Over recent years, with the rapid development of economy and the further integration of the union, the European population is migrating increasingly frequently either to land a promising job or simply for a better living environment across the boundaries. In the meantime, the immigrants across the world and refugees mainly from the neighbouring countries are constantly swarming in the membering neighbour countries. According to the European Council, there are currently more than 50 million people in Europe living in a country which they were not born in. Regardless of origin, nationality, ethnicity, cultural background, and religion, all the migrant population needs to settle down and lead a life in the community irrespective of their various means of setting foot on the land. Whether willingly or reluctantly, they need to communicate with the people and find their own niche in the new society. Either for better understanding and integration into the society or for a decent job and life, the migrant population is required to acquire certain local language and improve their language skills. Constant language learning and improving proves to be essential to ensure them have the basic skills needed to remain employable and competitive. As one of key skills on job market, the importance of multilingual skill is becoming increasingly evident and widely recognized by the migrant population.

Apart from the normal immigration either among EU or other continents, the refugees and asylum seekers in recent years are becoming another import source of migrant population. It is reported in 2015 more than one million refugees from the neighbouring countries came to Europe. Even after the "refugee crisis", people are still fleeing the warring and conflict countries and zones in the Middle East like Syria in great numbers, seeking a shelter and safer life across boundaries in Europe. And only in the first six weeks of 2016, as many as 80,000 refugees arrived by sea. A big migrant population like this would undoubtly pose a great challenge to the local education. Facing the challenge in education, both the member states and the Council of Europe need to take

LIU Xu-liang, associate professor, MA, Foreign Language Department, University of Chinese Academy of Social Sciences, Beijing, China.

This paper is the research results of 2018 UCASS Academic Innovation Project. 
substantial measures and develop flexible approaches to accommodate and improve the refugees' skills for better life and work. Refugees should by no means be barred from further study or work.

To help the migrating population acquire and sharpen their language skills, education in various levels and forms is functioning and yet to be put in due place. Just as the normal national education, migrant population education should be an integral part of the education strategy either for the European Union or for the member states. Both are enshrined with the responsibility to assist and support the receiving population to settle and work peacefully and fruitfully. Here by migrant population the author refers to all of those who travel, live, and work among the European member states and usually for a relatively long period of time. Therefore, migrant workers, immigrants, and refugees are all involved in the research project and will be given due attention and analysis.

\section{Differences Among the Migrant Population}

People came from different cultures and are of different ethnicities which decide they hold different ideologies, values, and beliefs.

- They are of different educational backgrounds with a wide range of literacy levels.

- They speak different languages and their learning skills vary greatly.

- They are of different ages and have different language conditions and environments.

- They work in different professions and have different language pursuit.

\section{Similarities Among the Migrant Population}

- They share the same need to possess the basic language competence to live and work in the host country and community.

- They are granted the equal right of learning and working either in the European convention or charter. According to ECT 093 (24.XI.1977) Article 14, migrant workers and members of their families are officially entitled, on the same basis and under the same conditions as national workers, to general education and vocation training. And ECT 163 (3.V.1996) Article 19 of the European Social Charter (revised) stipulates that the target nation undertake: Proposition 11, to promote and facilitate the teaching of the national language of the receiving state or, if there are several, one of these languages, to migrant workers and members of their families.

Therefore, the member states of the European Council share the same goal to promote access to general and vocational schools, and they are required to offer the teaching and learning opportunities of its language. To enhance mutual cooperation and share experience among the member states, three intergovernmental conferences to date (2008, 2010, and 2014) have been convened of which the focus and priority varies from the ways of evaluating policy and practice (2010) to quality in the linguistics integration of adult migrants; from values to policy and practice (2014) . Meanwhile, a project of Linguistic Integration of Adult Migrants (LIAM) was launched by the Council of Europe which is committed to the cause of migrant multilingual competence. Its main role is to help and coordinate member states to develop language policies based on the shared values of EU: respect for human rights, democracy and the rule of law, and pool and disseminate their innovative and productive experiences and resources.

\section{Raising the Threshold of Immigration and Migration}

In recent years, most European countries are seemingly raising the threshold of entry with a language 
proficiency requirement. Candidates are usually required to pass a language test in order to secure a visa, long-term residence, or citizenship. According to the survey report of 2013, 29 of the 36 Council of Europe member states required to take a language course and/or a language test for the legal right of entry, residence, or citizenship.

Table 1

Number of Countries Attaching Different CEFR Levels to the Granting of a Residence Permit and Citizenship in 2013

\begin{tabular}{lll}
\hline CEFR level & Residence permit & Citizenship \\
\hline A1.1 & 1 & 0 \\
A1 & 1 & 1 \\
A2 & 7 & 4 \\
B1 & 3 & 8 \\
A1/A2 & 0 & 0 \\
A2/B1 & 1 & 3 \\
Total number of countries & 13 & 16 \\
\hline
\end{tabular}

\section{School and Formal Education}

The European Area of Recognition Manual: standards and guidelines on recognition (2012) advises on access to higher education for those without adequate documentation, including refugees. Most of the host country schools hold a positive attitude and open their doors to the migrant children. Only in the year of 2015 alone, 3,000 unaccompanied refugee minors enter Finland and 14,000 enter Sweden to seek asylum. Also in Finland, 20 folk high schools opened their doors to accommodate over 500 young refugees. In Sweden, more than 30 folk high schools worked together with local youth organizations on a project called "Include More" to develop strategies for the inclusion of refugees. In order to determine the proficiency and offer appropriate types of support, about one third of European countries conduct assessment tests for the newly arrived students in terms of schooling language. And in some cases, separate classes are established to help students catch up and integrate into mainstream classrooms with intensive language teaching. Some countries even provide mother tongue or bilingual subject teaching such as Germany, Austria, Switzerland, and Turkey. The migrant children in the formal schools can generally receive quality education as well as the locals without bias and can even get continuing professional support. There are still some exceptions where the local schools are ready to accept the migrant children, but the governments hold an opposite stance and reject to receive the asylum-seekers as in country of Spain.

\section{Social and Informal Pursuit of Building Mobile Linguistic Diversity}

Since the 1970s the Council of Europe has always been promoting the idea of lifelong language learning (LLP). In the year 2000, the Lifelong Learning Programme was formally established with an aim to achieve the strategic goal set by The Lisbon European Council to build European Union into a most competitive and dynamic economy in the world. One important task is to help the labour force master some basic skills, among which multilingual skill is a key one. The final goal is build European community into a society which enables people, at any stage of their life, to take part in stimulating learning experiences. As an important contributor and stakeholder of a multicultural and multilanguage society, the migrants' proficiency in the language of the host country should also continue to develop over the course of their lifetime. 


\section{Joint Efforts and Support for Multi-linguistic Pursuit and Improvement}

In order to better implement language policies and promote innovative approaches in the field of modern language learning and teaching, the devoted project of ECML (European Centre for Modern Languages) is established to support the language concerning efforts and commitments. As a multi-functional platform, many language policies, guidance, approaches, projects, events, and resources are accessible for language reference and support. At the state level, the governments and authorities also launch some supporting programs to help migrants command the local language well, such as the L-Pack 2 in Italy which is funded with the Lifelong Learning Programme and aims to offer a "Citizenship language pack for migrants in Europe". And Lithuania is a country of possibilities in Lithuania which was designed to help refugees become more self-reliant by gaining qualifications in a specific field and to contribute to society. All these programs and initiatives share the same goal of improving the qualification levels of the migrant population in terms of residence, citizenship, education, life, and employability.

\section{Online Linguistic Support as Important Means of Assessment Reference (CEFR)}

As a platform of language proficiency reference and assessment, the CEFR project (the Common European Framework of Reference for Languages) was first launched in 2001. Nowadays it has become well accepted and widely adopted throughout Europe with the availability of almost 40 languages. Besides its conducive role in formal education, its reference scales and levels can also be utilized by the migrant population in their foreign language progress. The Council of Europe requires the member states to tailor the migrant language tests to better adapt to the scales and levels of the CEFR as a means of promoting and measuring language proficiency, and gradually develop it into not simply a measure of linguistic ability but a mechanism indicative of the degree of integration. Currently, the CEFR has become the main language proficiency reference for the long-term residents in the European Union.

\section{Online Linguistic Support as Important Means of Learning Promotion (Erasmus+ and ELP)}

The innovative and pioneering influence of the Erasmus+ programme. Poor language competences is one of the major barriers to refrain the European people from free education, profession, and communication. The Erasmus+ programme is launched to offer linguistic support to the common European citizens when they are studying, working, travelling, or volunteering abroad. Facilitating language learning and promoting linguistic diversity are two specific objectives of this programme. People can improve their learning performance via the Erasmus+ Online Linguistic Support (OLS), which is featured with easy access, free of charge, live coaching, peer learning, and flexibility of e-learning. This platform involves a random assessment of language competences and optional language courses. All EU official languages are expected to be offered and be available on the OLS system by 2020. Participants in the Erasmus+ programme just need to register for the first time and get access to the knowledge of target language and follow an interactive language course at their own pace. The Erasmus+ program requires participants take the assessment at least twice prior and post to their mobility with an aim to follow their progress in the language. The online assessment is based on CEFR assessing participants' language skills including listening, reading, and writing. They can get evidence of their language skills or use it as a tool to study, carry out a traineeship or volunteering abroad. And the receiving country or institution can use it to check whether the candidate reached the recommended level stipulated before agreement with the start of the mobility. One advantage of this assessment is randomness and personal customization. People can take the test at any time and save the test results. The testing item is adaptive and 
tailor-made. When people take a test, the difficulty of the questions is based on the answers to previous questions, so the candidate's linguistic ability is measured with a smart and progressive technology to ensure the precision of one's language proficiency.

European Language Portfolio (ELP). ELP is another program launched to support the development of language skills of adult migrants. It is designed to help build learner autonomy, plurilingualism, and intercultural awareness. It allows users to record their language learning achievements and their experience of learning and using languages. As a means of recording and tracking progress, it can be also used by migrants to relate their progress to the proficiency levels of the CEFR.

\section{Challenges Confronted by the EU Migrant Language Education}

\section{Multi-lingual and Multi-cultural Teachers Are Scarce}

To teach students who do not speak the language of schooling, teachers should have some general knowledge of the migrant students' native language and culture, and prospective teachers should undertake some systematic trainings and qualifications on second language acquisition before they work with migrant students. However, most of the European countries currently do not have any recommendations or requirements for migrant teachers. And only two countries (Denmark and Austria) have specified and explicit training requirements for all prospective teachers.

\section{Fundings Fall Short for More Projects and Opportunities}

Given the harsh fact of migrant explosion and urgent need for integration, there is an increased demand for budget increase of migrants and refugees. Just take Erasmus+ programme for example, as an important means of helping migrants increase education participation levels, its budget of adult education is currently $5 \%$. It is assumed a $15 \%$ increase which is desired to reach the goal of $15 \%$ life-long learning participation rate by 2020 (as stipulated in the ET2020).

\section{Conclusion}

Language education plays a vital role in the building of an active and dynamic migrant work force which is crucial for the local prosperity and realization of the EU 2020 Strategy. Apart from the learning of the language of the host country, the migrants' mother tongue should also be attached equal and due importance which is believed to be beneficial to the cognitive development and cultural identity. Multilingualism is regarded a key principle in the EU language policy and strategy. Satisfyingly, with years of efforts and dedication through the whole European Union, the migrant language education is transferring from availability to quality (Resolution 2006, 2014). And the working focus and priority of the European Council is shifting from the education of the overall population to some minor specific disadvantaged groups (Resolution 1811, 2011).

\section{References}

Council of Europe. (2014a). Linguistic integration of adult migrants: Final report on the 3rd council of Europe survey. Language Policy Unit, Strasbourg. Project LIAM. Retrieved from www.coe.int/lang-migrants

Council of Europe. (2014b). The linguistic integration of adult migrants-from one country to another, from one language to another. ISBN 978-92-871-7871-8.

European Commission/EACEA/Eurydice. (2017). Key data on teaching languages at school in Europe-2017 edition. Eurydice Report. Luxembourg: Publications Office of the European Union. 
ECML.

(n.d.).

Retrieved

from

http://www.ecml.at/Thematicareas/Migrantlanguageeducation/tabid/1624/language/en-GB/Default.aspx

Resolution 1811. (2011). Protecting migrant women in the labour market.

Resolution 2006. (2014). Integration of migrants in Europe: The need for a proactive, long-term and global policy.

Recommendation 2034. (2014). Integration tests: Helping or hindering integration? 